\title{
Article \\ Undifferentiated Embryonal Sarcoma of the Liver in Children Versus Adults: A National Cancer Database Analysis ${ }^{\dagger}$
}

\author{
Ioannis A. Ziogas ${ }^{1}{ }^{\mathbb{D}}$, Irving J. Zamora ${ }^{2}$, Harold N. Lovvorn III ${ }^{2} \mathbb{D}$, Christina E. Bailey $^{3}$ \\ and Sophoclis P. Alexopoulos ${ }^{1, *}$
}

1 Department of Surgery, Division of Hepatobiliary Surgery and Liver Transplantation, Vanderbilt University Medical Center, Nashville, TN 37232, USA; ioannis.a.ziogas@vumc.org

2 Department of Pediatric Surgery, Monroe Carell, Jr. Children's Hospital at Vanderbilt, Nashville, TN 37232, USA; irving.zamora@vumc.org (I.J.Z.); harold.lovvorn@vumc.org (H.N.L.III)

3 Department of Surgery, Division of Surgical Oncology, Vanderbilt University Medical Center, Nashville, TN 37232, USA; christina.e.bailey@vumc.org

* Correspondence: sopho.alexopoulos@vumc.org; Tel.: +1-615-936-0420

+ Part of the findings were orally presented at the American College of Surgeons Clinical Congress on 3 October 2020.

check for updates

Citation: Ziogas, I.A.; Zamora, I.J.; Lovvorn III, H.N.; Bailey, C.E.; Alexopoulos, S.P. Undifferentiated Embryonal Sarcoma of the Liver in Children Versus Adults: A National Cancer Database Analysis ${ }^{\dagger}$. Cancers 2021, 13, 2918. https://doi.org/ 10.3390/cancers 13122918

Academic Editors: J. Chad Brenner and Günther H.S. Richter

Received: 13 April 2021

Accepted: 4 June 2021

Published: 11 June 2021

Publisher's Note: MDPI stays neutral with regard to jurisdictional claims in published maps and institutional affiliations.

Copyright: (C) 2021 by the authors. Licensee MDPI, Basel, Switzerland. This article is an open access article distributed under the terms and conditions of the Creative Commons Attribution (CC BY) license (https:/ / creativecommons.org/licenses/by/ $4.0 /)$.
Simple Summary: Undifferentiated embryonal sarcoma of the liver (UESL) is the third most common type of liver malignancy in the pediatric population, following hepatoblastoma and hepatocellular carcinoma. In comparison to children, UESL is an extremely rare malignancy in adults. Although historically treatment was limited to surgical resection and survival was poor, the combination of surgical treatment and chemotherapy recently has led to improved survival. We attempted to examine the characteristics and outcomes of children and adults with UESL in a contemporary U.S. cohort. We showed that children demonstrate favorable survival with multimodal treatment, while adults demonstrate inferior outcomes and future research endeavors should focus on refining currently available treatment modalities for adults with UESL.

Abstract: This study evaluates the clinicopathological characteristics and outcomes of children vs. adults with undifferentiated embryonal sarcoma of the liver (UESL). A retrospective analysis of 82 children ( $<18$ years) and 41 adults $(\geq 18$ years) with UESL registered in the National Cancer Database between 2004-2015 was conducted. No between-group differences were observed regarding tumor size, metastasis, surgical treatment, margin status, and radiation. Children received chemotherapy more often than adults $(92.7 \%$ vs. $65.9 \% ; p<0.001)$. Children demonstrated superior overall survival vs. adults (log-rank, $p<0.001$ ) with 5 -year rates of $84.4 \%$ vs. $48.2 \%$, respectively. In multivariable Cox regression for all patients, adults demonstrated an increased risk of mortality compared to children $(p<0.001)$, while metastasis was associated with an increased $(p=0.02)$ and surgical treatment with a decreased $(p=0.001)$ risk of mortality. In multivariable Cox regression for surgically-treated patients, adulthood $(p=0.004)$ and margin-positive resection $(p=0.03)$ were independently associated with an increased risk of mortality. Multimodal treatment including complete surgical resection and chemotherapy results in long-term survival in most children with UESL. However, adults with UESL have poorer long-term survival that may reflect differences in disease biology and an opportunity to further refine currently available treatment schemas.

Keywords: embryonal sarcoma; liver sarcoma; hepatic sarcoma; liver cancer; National Cancer Database

\section{Introduction}

Undifferentiated embryonal sarcoma of the liver (UESL) is the third most common type of liver malignancy in the pediatric population, following hepatoblastoma and hepatocellular carcinoma, and became a distinct pathology after the report of Stocker and Ishak in 1978 [1]. Due to a low estimated annual incidence of one per million [2], there are only a 
few reported cases in the literature. It is a highly aggressive malignancy of mesenchymal origin with a tendency for local and distant metastasis [3]. Typically, UESL are large tumors with an average diameter of 10-30 cm [4]. The clinical manifestations (abdominal pain, fever, anorexia) and the radiographic characteristics (solid and cystic components) are nonspecific, and thus UESL may pose a significant diagnostic challenge that can lead to a delay in appropriate management [3-9]. Although historically treatment was limited to surgical resection and overall survival (OS) was poor [1], the combination of surgical treatment and chemotherapy recently has led to improved OS [10-15].

In comparison to children, UESL is an extremely rare malignancy in adults [16]. According to a recent systematic review and pooled analysis, less than 90 adult UESL cases have been published between 1973-2019 [6]. The authors reported that, compared to children, a higher proportion of adults presented with metastatic disease and received no surgical treatment with 5-year OS rates of $49.5 \%$ vs. $79.9 \%$, respectively [6]. However, that cohort was comprised of patients managed over different time periods and in different healthcare systems. Therefore, we aimed to evaluate the characteristics and compare OS between pediatric and adult UESL patients in the United States over a contemporary era, and to identify risk factors of mortality. We hypothesized that adults with UESL present with more advanced disease and demonstrate inferior OS compared to children with UESL.

\section{Materials and Methods}

\subsection{Data Source and Patient Population}

We included all patients with UESL registered in the National Cancer Database (NCDB) between 2004-2015. The NCDB is a joint project of the Commission on Cancer of the American College of Surgeons and the American Cancer Society and incorporates about $70 \%$ of all newly diagnosed cancers in more than 1500 hospitals accredited by the Commission on Cancer in the United States [17]. It includes data on demographics, clinicopathological characteristics, tumor characteristics, management, and survival [18].

For the present study, we used the NCDB Participant Use Data File to identify both children ( $<18$ years) and adults ( $\geq 18$ years) with UESL using the International Classification of Diseases for Oncology, 3rd Edition, with the combination of liver site code "C22.0" and the histology codes "8805" and "8991". We excluded patients with missing data about the time between diagnosis and death or last patient contact, or with missing data about the vital status at last patient contact. Figure 1 depicts our cohort assembly. Institutional Review Board approval was not required as all data were de-identified.

\subsection{Covariates and Outcomes}

We extracted the following patient demographic data: age, sex, race, insurance status, and year of diagnosis. Clinicopathological and treatment-related data that were extracted included tumor size, regional lymph node status, metastasis, extent of surgical treatment (wedge/segmental resection, lobectomy, extended lobectomy, resection not otherwise specified, liver transplantation (LT)), resection margin status, receipt of chemotherapy, systemic therapy (chemotherapy)-surgery sequence, and receipt of radiotherapy. We used the number of days between diagnosis and chemotherapy initiation when the systemic therapy (chemotherapy)-surgery sequence data were not available. OS was defined as the time from diagnosis until death or last patient contact and was our primary outcome. 


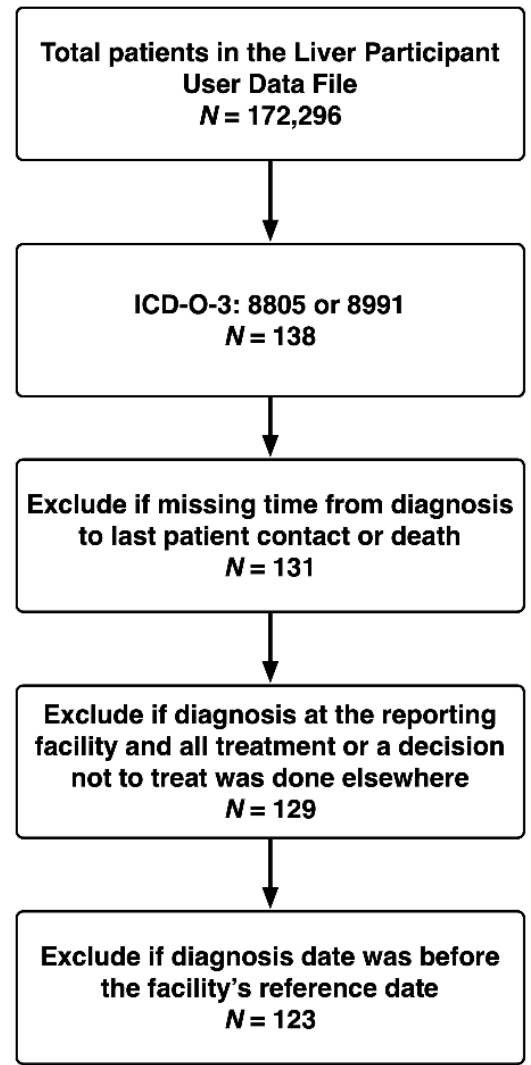

Figure 1. Assembly of Analysis Cohort.

\subsection{Statistical Analysis}

Continuous variables were summarized as medians (interquartile ranges (IQRs)) and were compared using the Mann-Whitney $\mathrm{U}$ test, while categorical variables were summarized as frequencies (\%) and were compared using the chi-square test. The Kaplan-Meier method was employed for survival analysis, and we performed pairwise comparisons using the log-rank test. We also fitted Cox regression models to obtain the hazard ratio (HR) and a 95\% confidence interval (CI). In order to avoid the inferential limitations of selecting variables for multivariable models based on stepwise procedures or univariable comparisons, we prespecified the variables to be included in our multivariable models [19]. Our first multivariable model assessing factors associated with mortality in the entire cohort incorporated the following variables: age group (children vs. adults), metastatic status at the time of diagnosis, surgical treatment, chemotherapy, and radiation. Our second multivariable model assessing factors associated with mortality in the surgical cohort incorporated the following variables: age group (children vs. adults), metastatic status at the time of diagnosis, chemotherapy, radiation, tumor size, and surgical margin status. All statistical analyses were conducted using Stata IC 16.0 (StataCorp LLC, College Station, TX, USA). All $p$-values were based on two-sided statistical tests, and significance was set at $<0.05$.

\section{Results}

\subsection{Patient Demographics and Treatment Modalities}

Overall, 123 patients with UESL (82 children and 41 adults) were identified in the NCDB (Table 1). The median age was 11.0 years (IQR: 6.0-23.0), more than half of the patients were female $(57.7 \%)$, and $69.9 \%$ were of Caucasian race. Median tumor size was $14.0 \mathrm{~cm}$ (IQR: 10.0-16.0), metastasis at diagnosis was seen in $13.8 \%$ of the patients, and $82.9 \%$ of them underwent surgical treatment (LT in 4 children). When the cohort was separated into age groups, children were less often female than adults (50.0\% vs. $73.2 \%$; 
$p=0.01$ ), while no statistically significant differences were observed between the two comparison groups regarding race, insurance status, tumor size, regional lymph node status, metastasis, surgical treatment and margin status, and receipt of radiation. However, the proportion of children who received chemotherapy was higher than that of the adults $(92.7 \%$ vs. $65.9 \% ; p<0.001)$. Of the 64 children receiving both surgery and chemotherapy, $14(22 \%)$ had neoadjuvant, $37(58 \%)$ had adjuvant, and $13(20 \%)$ had both neoadjuvant and adjuvant therapy. Of the 23 adults receiving both surgery and chemotherapy, $1(4 \%)$ had neoadjuvant and $22(96 \%)$ had adjuvant therapy.

Table 1. Cohort characteristics.

\begin{tabular}{|c|c|c|c|c|}
\hline Characteristics & Total $(n=123)$ & Children $(n=82)$ & Adults $(n=41)$ & $p$ Value \\
\hline Age (years) & $11.0(6.0-23.0)$ & $7.5(5.0-11.0)$ & $36.0(23.0-62.0)$ & $<0.001$ \\
\hline Sex & & & & 0.01 \\
\hline Female & $71(57.7 \%)$ & $41(50.0 \%)$ & $30(73.2 \%)$ & \\
\hline Male & $52(42.3 \%)$ & $41(50.0 \%)$ & $11(26.8 \%)$ & \\
\hline Race & & & & 0.22 \\
\hline African American & $24(19.5 \%)$ & $13(15.9 \%)$ & $11(26.8 \%)$ & \\
\hline Caucasian & $86(69.9 \%)$ & $60(73.2 \%)$ & $26(63.4 \%)$ & \\
\hline Other & $9(7.3 \%)$ & $5(6.1 \%)$ & $4(9.8 \%)$ & \\
\hline Unknown & $4(3.3 \%)$ & $4(4.9 \%)$ & $0(0.0 \%)$ & \\
\hline Insurance status & & & & 0.97 \\
\hline Not insured & $3(2.4 \%)$ & $2(2.4 \%)$ & $1(2.4 \%)$ & \\
\hline Private & $63(51.2 \%)$ & $41(50.0 \%)$ & $22(53.7 \%)$ & \\
\hline Public & $53(43.1 \%)$ & $36(43.9 \%)$ & $17(41.5 \%)$ & \\
\hline Unknown & $4(3.3 \%)$ & $3(3.7 \%)$ & $1(2.4 \%)$ & \\
\hline Tumor size $(\mathrm{cm})(n=108)$ & $14.0(10.0-16.0)$ & $14.0(11.0-15.9)$ & $14.8(7.6-19.5)$ & 0.90 \\
\hline Regional lymph node status & & & & 0.44 \\
\hline Negative & $30(24.4 \%)$ & $18(22.0 \%)$ & $12(29.3 \%)$ & \\
\hline Positive & $4(3.3 \%)$ & $3(3.7 \%)$ & $1(2.4 \%)$ & \\
\hline No nodes were examined & $86(69.9 \%)$ & $60(73.2 \%)$ & $26(63.4 \%)$ & \\
\hline Unknown & $3(2.4 \%)$ & $1(1.2 \%)$ & $2(4.9 \%)$ & \\
\hline Metastasis at diagnosis & & & & 0.33 \\
\hline No & $101(82.1 \%)$ & $65(79.3 \%)$ & $36(87.8 \%)$ & \\
\hline Yes & $17(13.8 \%)$ & $14(17.1 \%)$ & $3(7.3 \%)$ & \\
\hline Unknown & $5(4.1 \%)$ & $3(3.7 \%)$ & $2(4.9 \%)$ & \\
\hline Chemotherapy & & & & $<0.001$ \\
\hline No & $18(14.6 \%)$ & $4(4.9 \%)$ & $14(34.2 \%)$ & \\
\hline Yes & $103(83.7 \%)$ & $76(92.7 \%)$ & $27(65.9 \%)$ & \\
\hline Unknown & $2(1.6 \%)$ & $2(2.4 \%)$ & $0(0.0 \%)$ & \\
\hline Radiation & & & & 0.20 \\
\hline No & $101(82.1 \%)$ & $64(78.1 \%)$ & $37(90.2 \%)$ & \\
\hline Yes & $21(17.1 \%)$ & $17(20.7 \%)$ & $4(9.8 \%)$ & \\
\hline Unknown & $1(0.8 \%)$ & $1(1.2 \%)$ & $0(0.0 \%)$ & \\
\hline Surgical treatment & & & & 0.31 \\
\hline No & $21(17.1 \%)$ & $12(14.6 \%)$ & $9(22.0 \%)$ & \\
\hline Yes & $102(82.9 \%)$ & $70(85.4 \%)$ & $32(78.0 \%)$ & \\
\hline
\end{tabular}


Table 1. Cont.

\begin{tabular}{|c|c|c|c|c|}
\hline Characteristics & Total $(n=123)$ & Children $(n=82)$ & Adults $(n=41)$ & $p$ Value \\
\hline Type of surgical treatment $(n=102)$ & & & & 0.29 \\
\hline Wedge/segmental resection & $30(29.4 \%)$ & $22(31.4 \%)$ & $8(25.0 \%)$ & \\
\hline Lobectomy & $43(42.2 \%)$ & $28(40.0 \%)$ & $15(46.9 \%)$ & \\
\hline Extended lobectomy & $14(13.7 \%)$ & $7(10.0 \%)$ & $7(21.9 \%)$ & \\
\hline Resection, not otherwise specified & $11(10.8 \%)$ & $9(12.9 \%)$ & $2(6.3 \%)$ & \\
\hline Liver transplantation & $4(3.9 \%)$ & $4(5.7 \%)$ & $0(0.0 \%)$ & \\
\hline Margin status $(n=102)$ & & & & 1.00 \\
\hline No residual tumor & $71(69.6 \%)$ & $48(68.6 \%)$ & $23(71.9 \%)$ & \\
\hline Residual tumor & $17(16.7 \%)$ & $12(17.1 \%)$ & $5(15.6 \%)$ & \\
\hline Not evaluable/unknown & $14(13.7 \%)$ & $10(14.3 \%)$ & $4(12.5 \%)$ & \\
\hline $\begin{array}{l}\text { Chemotherapy/surgery sequence } \\
\qquad(n=102)\end{array}$ & & & & $<0.001$ \\
\hline None & $13(12.8 \%)$ & $4(5.7 \%)$ & $9(28.1 \%)$ & \\
\hline Neoadjuvant & $15(14.7 \%)$ & $14(20.0 \%)$ & $1(3.1 \%)$ & \\
\hline Adjuvant & $59(57.8 \%)$ & $37(52.9 \%)$ & $22(68.8 \%)$ & \\
\hline Neoadjuvant and adjuvant & $13(12.8 \%)$ & $13(18.6 \%)$ & $0(0.0 \%)$ & \\
\hline Unknown & $2(2.0 \%)$ & $2(2.9 \%)$ & $0(0.0 \%)$ & \\
\hline $\begin{array}{l}\text { Follow-up time after diagnosis } \\
\text { (months) }\end{array}$ & $48.1(20.2-92.6)$ & $61.2(22.9-102.9)$ & $29.6(12.0-71.4)$ & 0.007 \\
\hline
\end{tabular}

\subsection{Overall Survival}

The 1-, 3-, and 5-year OS rates in the entire cohort were $86.8 \%, 75.4 \%$, and $71.7 \%$, respectively. Children demonstrated superior OS compared to adults (log-rank test: $p<0.001$ ) with 5 -year OS rates of $84.4 \%$ and $48.2 \%$, respectively (Figure $2 \mathrm{~A}$ ). Metastatic disease resulted in decreased survival compared to non-metastatic disease (5-year OS rates of 53.1\% and $76.0 \%$, respectively; log-rank test: $p=0.01$; Figure 2B). Surgically treated patients exhibited superior OS compared to those treated non-operatively (5-year OS rates of $79.1 \%$ and $36.3 \%$, respectively; log-rank test: $p<0.001$; Figure 2C). Patients receiving chemotherapy exhibited superior OS compared to those who did not receive chemotherapy (5-year OS rates of $74.9 \%$ and $50.3 \%$, respectively; log-rank test: $p=0.01$; Figure 2D). Four children who underwent neoadjuvant chemotherapy and LT were alive over a follow-up period of 17-80 months post-LT.

In multivariable Cox regression analysis for the entire cohort (Table 2), adults demonstrated 5.35 times higher risk of mortality (95\% CI: 2.24-12.77; $p<0.001)$ compared to children, while metastasis was also associated with an increased risk of mortality (HR $=3.34$, 95\% CI: 1.20-9.29; $p=0.02$ ). On the other hand, surgical treatment was associated with a survival benefit (HR $=0.21,95 \%$ CI: $0.09-0.52 ; p=0.001$ ). We next performed multivariable Cox regression analysis to identify risk factors of mortality in surgically-treated patients (Table 3). Being adult ( $\mathrm{HR}=10.68,95 \% \mathrm{CI}$ : $2.10-54.33 ; p=0.004)$ and having a marginpositive resection ( $\mathrm{HR}=5.41,95 \% \mathrm{CI}: 1.18-24.75 ; p=0.03)$ were identified as parameters independently associated with an increased risk of mortality. 


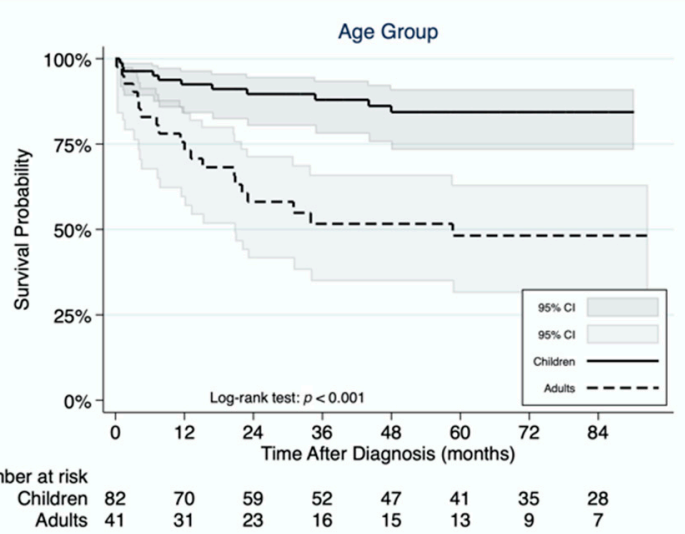

(c)

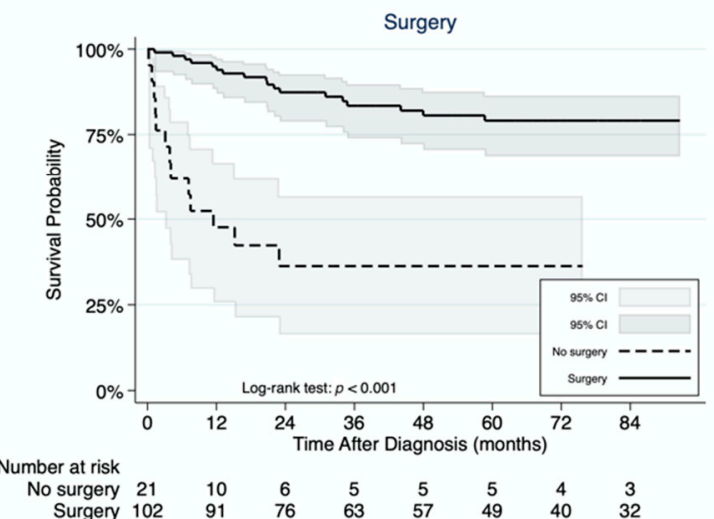

(B)

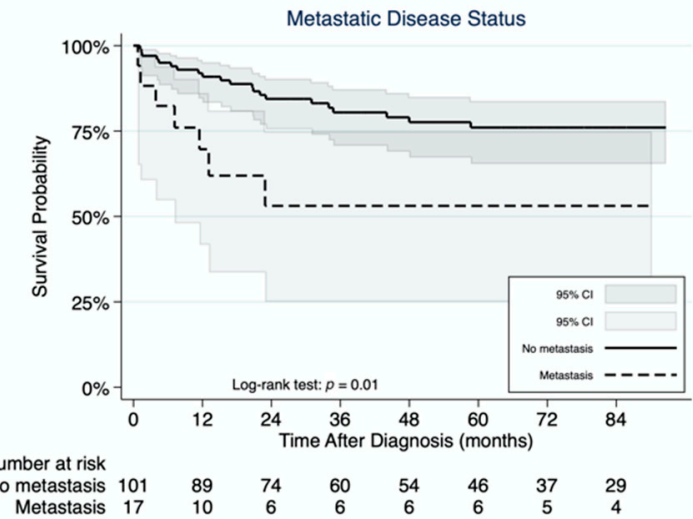

(D)

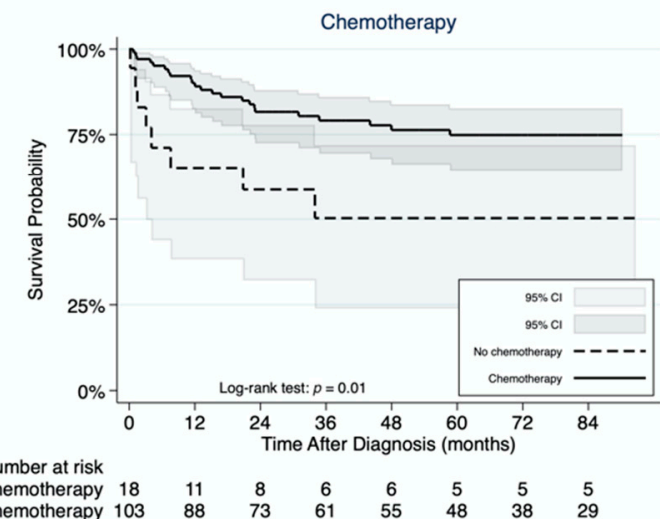

Figure 2. Kaplan-Meier curves demonstrating differences in overall survival for undifferentiated embryonal sarcoma of the liver between children and adults (A), between patients with and without metastasis at diagnosis (B), between patients undergoing surgery or not (C), and between patients receiving chemotherapy or not (D).

Table 2. Risk factors associated with mortality in the entire cohort.

\begin{tabular}{|c|c|c|c|c|c|c|}
\hline \multirow{2}{*}{ Characteristics } & \multirow{2}{*}{$n$} & \multicolumn{2}{|c|}{ Univariable } & \multirow{2}{*}{$n$} & \multicolumn{2}{|c|}{ Multivariable $(n=115)$} \\
\hline & & HR (95\% CI) & $p$ Value & & HR $(95 \%$ CI) & $p$ Value \\
\hline \multicolumn{7}{|l|}{ Age group } \\
\hline Children & 82 & Reference & - & 76 & Reference & - \\
\hline Adults & 41 & $4.36(2.08-9.11)$ & $<0.001$ & 39 & $\begin{array}{c}5.35 \\
(2.24-12.77)\end{array}$ & $<0.001$ \\
\hline \multicolumn{7}{|l|}{ Surgical treatment } \\
\hline No & 21 & Reference & - & 18 & Reference & - \\
\hline Yes & 102 & $0.16(0.08-0.34)$ & $<0.001$ & 97 & $0.21(0.09-0.52)$ & 0.001 \\
\hline \multicolumn{7}{|l|}{ Chemotherapy } \\
\hline No & 18 & Reference & - & 16 & Reference & - \\
\hline Yes & 103 & $0.36(0.16-0.81)$ & 0.01 & 99 & $0.59(0.22-1.60)$ & 0.30 \\
\hline \multicolumn{7}{|l|}{ Radiation } \\
\hline No & 101 & Reference & - & 94 & Reference & - \\
\hline Yes & 21 & $0.72(0.25-2.07)$ & 0.55 & 21 & $1.18(0.39-3.56)$ & 0.77 \\
\hline \multicolumn{7}{|l|}{$\begin{array}{l}\text { Metastasis at } \\
\text { diagnosis }\end{array}$} \\
\hline No & 101 & Reference & - & 98 & Reference & - \\
\hline Yes & 17 & $2.82(1.19-6.66)$ & 0.02 & 17 & 3.34 (1.20-9.29) & 0.02 \\
\hline
\end{tabular}


Table 3. Risk factors associated with mortality in surgically-treated patients.

\begin{tabular}{|c|c|c|c|c|c|c|}
\hline \multirow{2}{*}{ Characteristics } & \multirow{2}{*}{$n$} & \multicolumn{2}{|c|}{ Univariable } & \multirow{2}{*}{$n$} & \multicolumn{2}{|c|}{ Multivariable $(n=79)$} \\
\hline & & HR $(95 \%$ CI) & $p$ Value & & HR $(95 \%$ CI) & $p$ Value \\
\hline \multicolumn{7}{|l|}{ Age group } \\
\hline Children & 70 & Reference & - & 53 & Reference & - \\
\hline Adults & 32 & $\begin{array}{c}4.95 \\
(1.85-13.23)\end{array}$ & 0.001 & 26 & $\begin{array}{c}10.68 \\
(2.10-54.33)\end{array}$ & 0.004 \\
\hline \multicolumn{7}{|l|}{ Surgical margins } \\
\hline No residual tumor & 72 & Reference & - & 64 & Reference & - \\
\hline Residual tumor & 17 & $2.08(0.71-6.08)$ & 0.18 & 15 & $\begin{array}{c}5.41 \\
(1.18-24.75)\end{array}$ & 0.03 \\
\hline Tumor size $(\mathrm{cm})$ & 92 & $1.02(0.99-1.04)$ & 0.09 & 79 & $1.00(0.97-1.04)$ & 0.89 \\
\hline \multicolumn{7}{|l|}{ Chemotherapy } \\
\hline Neoadjuvant and adjuvant & 13 & Reference & - & 12 & Reference & - \\
\hline None & 13 & $1.13(0.23-5.62)$ & 0.88 & 9 & $0.43(0.04-5.26)$ & 0.51 \\
\hline Neoadjuvant & 15 & $0.55(0.09-3.28)$ & 0.51 & 9 & $\begin{array}{c}1.24 \\
(0.11-14.50)\end{array}$ & 0.86 \\
\hline Adjuvant & 59 & $0.73(0.20-2.65)$ & 0.63 & 49 & $0.25(0.03-1.84)$ & 0.18 \\
\hline \multicolumn{7}{|l|}{ Radiation } \\
\hline No & 82 & Reference & - & 63 & Reference & - \\
\hline Yes & 19 & $0.92(0.27-3.18)$ & 0.90 & 16 & $0.51(0.07-3.52)$ & 0.49 \\
\hline \multicolumn{7}{|l|}{ Metastasis at diagnosis } \\
\hline $\mathrm{No}$ & 90 & Reference & - & 72 & Reference & - \\
\hline Yes & 10 & $1.45(0.33-6.31)$ & 0.62 & 7 & $\begin{array}{c}4.29 \\
(0.59-30.89)\end{array}$ & 0.15 \\
\hline
\end{tabular}

Abbreviations: $\mathrm{CI}$ = confidence interval; $\mathrm{HR}=$ hazard ratio.

\section{Discussion}

UESL accounts for around 9-15\% of pediatric liver cancers [1,4] and is only rarely reported in adults $[16,20]$. The most common treatment consists of surgical resection with the recent addition of chemotherapy [2,6]. The present study is unique in its inclusion of the largest number of UESL patients diagnosed and treated in a contemporary era and is the first to compare OS between children and adults with UESL in the United States. Moreover, our findings demonstrated that although the majority of patients are offered surgical treatment, adults with UESL were less commonly treated with chemotherapy compared to children despite similar tumor size and rates of metastatic disease. When adjusting for covariates, adults had a five- and ten-fold increased risk of mortality compared to children in the entire and surgical cohorts, respectively. Additionally, margin-negative resection is essential to achieve long-term OS.

Prognosis for UESL was historically considered to be dismal [1,21-23]. More recent reports have shown an improvement in OS [10,11,13,15,24-27], which has been mostly attributed to the increasing use of chemotherapy in conjunction with surgical treatment $[2,10,11]$. In a recent systematic review and pooled analysis of 308 patients (219 children and 89 adults), the 5-year OS rate was $65.8 \%$, and more specifically $70.4 \%$ for those receiving surgical treatment vs. $6.6 \%$ for those receiving no surgical treatment [6]. These authors further identified margin-negative resection, receipt of chemotherapy, and childhood as factors independently associated with an improved survival in surgicallytreated UESL patients. Using more homogeneous and contemporary data from the U.S., we showed that the 5-year OS rate for all UESL patients in the United States was 71.7\%, and $79.1 \%$ for those treated surgically vs. $36.3 \%$ for those not treated surgically. Although we also showed the association of margin-negative resection and childhood with improved OS, our results regarding the importance of adding chemotherapy and/or radiotherapy to the 
surgical treatment plan, as well as the setting of administration, were inconclusive. A recent literature review showed that approximately $26 \%$ of UESL patients receive neoadjuvant chemotherapy, while more than $70 \%$ receive adjuvant chemotherapy [27], which is consistent with our findings. A recent multicenter study from Europe reported on 25 patients who underwent primary resection $(n=12)$ or neoadjuvant chemotherapy $(n=13$; delayed resection was employed in 8 , while the other 5 remained inoperable); 20 patients received adjuvant chemotherapy [28]. The authors concluded that complete resection is vital for the management of UESL and that surgery plus multiagent chemotherapy can yield favorable long-term outcomes [28]. Currently, no chemotherapy protocol is established for UESL [28], while the most commonly used agents include vincristine, ifosfamide, and doxorubicin $[6,27,28]$. Additionally, radiation therapy has only been scarcely used for UESL according to both our findings (17\%) and the literature $(15-16 \%)[2,6,27]$. Due to the lack of recent studies and the low incidence of this disease, multicenter prospective studies comparing surgery alone vs. surgery plus chemotherapy over a contemporary era are required to draw more robust conclusions about the effect of chemotherapy on OS. Additionally, immunotherapy constitutes another area that future research endeavors could focus on [29].

In general, UESL patients present with an abdominal mass and pain along with anorexia and weight loss [6,30]. Laboratory liver tests and tumor markers are typically normal, while elevated liver enzymes and cancer antigen 125 have been described in a few cases [3,4,30,31]. Additionally, fever and an increase in C-reactive protein, erythrocyte sedimentation rate, and leukocytes may be seen in cases of hemorrhage or necrosis in the tumor [4]. Macroscopically, UESLs are well-circumscribed with cystic and solid components of gray-white gelatinous areas with or without red and yellow hemorrhagic and necrotic parts [30,32]. Microscopically, spindle or stellate cells with ill-defined borders, hyperchromatic nuclei, inconspicuous nucleoli, and eosinophilic PAS-positive and diastaseresistant cytoplasmic globules along with multinucleated giant cells in a myxoid matrix are typically seen $[3,30,32]$. Although the immunohistochemical pattern is not specific, markers of histiocytic, muscle, and epithelial origin may be identified, such as vimentin, alpha-1 antitrypsin, desmin, and CD68 [4,33-36].

Although the importance of resection with negative margins in OS is unquestionable [28], data suggest that patients with unresectable UESL can demonstrate long-term OS with LT. In our analysis, four children undergoing neoadjuvant chemotherapy plus LT were alive at 17-80 months post-LT. A United Network of Organ Sharing database analysis showed that out of 12 children undergoing LT for UESL, 11 survived and 1 died postoperatively [27]. In an older NCDB analysis, all 10 children undergoing LT were alive at 5 years [2]. A systematic review also showed that out of 14 patients (10 children and 4 adults) undergoing LT for UESL, 3 died [6]. Several other case reports and case series have also demonstrated the ability to achieve long-term survival for UESL with chemotherapy and either primary or salvage LT $[12,14,26,37,38]$. These findings validate the role of LT in the management of unresectable UESL.

Our study is the first to investigate the clinicopathological characteristics and outcomes of both children and adults with UESL in the United States over a recent era. We showed that children with UESL survive longer than adults with the 5-year OS rates being $84.4 \%$ and $48.2 \%$, respectively. This survival benefit persisted even when adjusting for covariates in both the entire cohort and in surgically-treated patients. The only previous study to investigate this comparison was a heterogenous cohort of systematically reviewed patients (1973-2019), which reported a 5-year OS of 79.9\% in children and $49.5 \%$ in adults with UESL [6]. The authors also reported that this benefit persisted in the multivariable analysis of patients undergoing partial hepatectomy [6]. Based on these findings, although similar in histology, UESL appears to be not only more rare but also more aggressive in adults compared to children irrespective of metastatic disease status and receipt of surgery and/or chemotherapy. Further research needs to be pursued to unveil the underlying etiology for this disparity in disease biology and to refine currently available treatment schemas for 
adults with UESL. It remains apparent that UESL should be considered in the differential diagnosis in children and particularly adults with an atypical presentation of a large liver lesion to schedule surgical treatment in a timely fashion.

The present study has certain limitations, mostly inherent to the nature of retrospective database analyses. The NCDB does not capture some clinically important data fields, such as staging of liver tumors according to the Children's Oncology Group or pretreatment extent of disease, chemotherapy regimen, alpha-fetoprotein level, and response of the tumor to chemotherapy. Therefore, we were not able to assess the impact of these variables on OS, while we also could not evaluate recurrence-free survival as tumor recurrence data were not available in the NCDB. Additionally, due to the rarity of the disease, the study sample is relatively small, and caution is warranted in the interpretation of the results.

\section{Conclusions}

In conclusion, UESL constitutes a rare entity typically exceeding $10 \mathrm{~cm}$ in tumor diameter. Although mostly seen in children, it should always be considered in the differential diagnosis of an atypical liver lesion in adults, due to its highly aggressive behavior and its association with an increased risk of mortality in this age group. Prompt management with surgical resection in cases of resectable UESL or LT in cases of unresectable or locally recurrent UESL is of paramount importance to achieve long-term OS. Multimodal treatment results in long-term OS in most children with UESL. However, adults with UESL have poorer outcomes that may reflect differences in disease biology and an opportunity to further refine currently available treatment modalities in this age group.

Author Contributions: Conceptualization, I.A.Z. and S.P.A.; methodology, I.A.Z.; software, I.A.Z., C.E.B., and S.P.A.; validation, I.J.Z., H.N.L.III, C.E.B., and S.P.A.; formal analysis, I.A.Z.; investigation, I.A.Z., I.J.Z., H.N.L.III, C.E.B., and S.P.A.; resources, C.E.B. and S.P.A.; data curation, I.A.Z.; writingoriginal draft preparation, I.A.Z., I.J.Z., and H.N.L.III; writing-review and editing, I.A.Z., I.J.Z., H.N.L.III, C.E.B., and S.P.A.; visualization, I.A.Z., I.J.Z., and H.N.L.III; supervision, S.P.A.; project administration, C.E.B. and S.P.A.; funding acquisition, not applicable. All authors have read and agreed to the published version of the manuscript.

Funding: This research received no external funding.

Institutional Review Board Statement: As this study utilized de-identified data, Institutional Review Board approval was not required.

Informed Consent Statement: Not applicable.

Data Availability Statement: The data that support the findings of this study are available from the Commission on Cancer's National Cancer Database (NCDB). They are de-identified patient level data that do not identify hospitals, health care providers, or patients as agreed to in the Business Associate Agreement that each Commission on Cancer accredited program has signed with the American College of Surgeons. Restrictions apply to the availability of these data, which were used under license for this study. Data are available at https://www.facs.org/quality-programs/cancer/ncdb/puf (accessed date: 21 January 2020) with the permission of the American College of Surgeons.

Acknowledgments: The data used in the study are derived from a de-identified NCDB file. The American College of Surgeons and the Commission on Cancer have not verified and are not responsible for the analytic or statistical methodology employed, or the conclusions drawn from these data by the investigator.

Conflicts of Interest: The authors declare no conflict of interest.

\section{References}

1. Stocker, J.T.; Ishak, K.G. Undifferentiated (embryonal) sarcoma of the liver: Report of 31 cases. Cancer 1978, 42, 336-348. [CrossRef]

2. Shi, Y.; Rojas, Y.; Zhang, W.; Beierle, E.A.; Doski, J.J.; Goldfarb, M.; Goldin, A.B.; Gow, K.W.; Langer, M.; Meyers, R.L.; et al. Characteristics and outcomes in children with undifferentiated embryonal sarcoma of the liver: A report from the National Cancer Database. Pediatr. Blood Cancer 2017, 64, 1-8. [CrossRef]

3. Pinamonti, M.; Vittone, F.; Ghiglione, F.; Borasi, A.; Silvestri, S.; Coverlizza, S. Unexpected Liver Embryonal Sarcoma in the Adult: Diagnosis and Treatment. Case Rep. Surg. 2018, 2018, 8362012. [CrossRef] [PubMed] 
4. Wei, Z.G.; Tang, L.F.; Chen, Z.M.; Tang, H.F.; Li, M.J. Childhood undifferentiated embryonal liver sarcoma: Clinical features and immunohistochemistry analysis. J. Pediatr. Surg. 2008, 43, 1912-1919. [CrossRef]

5. Massani, M.; Caratozzolo, E.; Baldessin, M.; Bonariol, L.; Bassi, N. Hepatic cystic lesion in adult: A challenging diagnosis of undifferentiated primary embryonal sarcoma. Il Giornale di Chirurgia 2010, 31, 225-228.

6. Wu, Z.; Wei, Y.; Cai, Z.; Zhou, Y. Long-term survival outcomes of undifferentiated embryonal sarcoma of the liver: A pooled analysis of 308 patients. ANZ J. Surg. 2020, 90, 1615-1620. [CrossRef]

7. Buetow, P.C.; Buck, J.L.; Pantongrag-Brown, L.; Marshall, W.H.; Ros, P.R.; Levine, M.S.; Goodman, Z.D. Undifferentiated (embryonal) sarcoma of the liver: Pathologic basis of imaging findings in 28 cases. Radiology 1997, 203, 779-783. [CrossRef]

8. Joshi, S.W.; Merchant, N.H.; Jambhekar, N.A. Primary multilocular cystic undifferentiated (embryonal) sarcoma of the liver in childhood resembling hydatid cyst of the liver. Br. J. Radiol. 1997, 70, 314-316. [CrossRef] [PubMed]

9. Chung, E.M.; Lattin, G.E.J.; Cube, R.; Lewis, R.B.; Marichal-Hernández, C.; Shawhan, R.; Conran, R.M. From the archives of the AFIP: Pediatric liver masses: Radiologic-pathologic correlation. Part 2. Malignant tumors. Radiographics 2011, 31, 483-507. [CrossRef]

10. Bisogno, G.; Pilz, T.; Perilongo, G.; Ferrari, A.; Harms, D.; Ninfo, V.; Treuner, J.; Carli, M. Undifferentiated sarcoma of the liver in childhood: A curable disease. Cancer 2002, 94, 252-257. [CrossRef]

11. Kim, D.-Y.; Kim, K.-H.; Jung, S.-E.; Lee, S.-C.; Park, K.-W.; Kim, W.-K. Undifferentiated (embryonal) sarcoma of the liver: Combination treatment by surgery and chemotherapy. J. Pediatr. Surg. 2002, 37, 1419-1423. [CrossRef]

12. Plant, A.S.; Busuttil, R.W.; Rana, A.; Nelson, S.D.; Auerbach, M.; Federman, N.C. A single-institution retrospective cases series of childhood undifferentiated embryonal liver sarcoma (UELS): Success of combined therapy and the use of orthotopic liver transplant. J. Pediatr. Hematol. Oncol. 2013, 35, 451-455. [CrossRef]

13. Ismail, H.; Dembowska-Bagińska, B.; Broniszczak, D.; Kaliciński, P.; Maruszewski, P.; Kluge, P.; Święszkowska, E.; Kościesza, A.; Lembas, A.; Perek, D. Treatment of undifferentiated embryonal sarcoma of the liver in children-single center experience. J. Pediatr. Surg. 2013, 48, 2202-2206. [CrossRef]

14. Merli, L.; Mussini, C.; Gabor, F.; Branchereau, S.; Martelli, H.; Pariente, D.; Guérin, F. Pitfalls in the surgical management of undifferentiated sarcoma of the liver and benefits of preoperative chemotherapy. Eur. J. Pediatr. Surg. 2015, 25, 132-137. [CrossRef]

15. Cao, Q.; Ye, Z.; Chen, S.; Liu, N.; Li, S.; Liu, F. Undifferentiated embryonal sarcoma of liver: A multi-institutional experience with 9 cases. Int. J. Clin. Exp. Pathol. 2014, 7, 8647. [PubMed]

16. Lenze, F.; Birkfellner, T.; Lenz, P.; Hussein, K.; Länger, F.; Kreipe, H.; Domschke, W. Undifferentiated embryonal sarcoma of the liver in adults. Cancer 2008, 112, 2274-2282. [CrossRef] [PubMed]

17. Boffa, D.J.; Rosen, J.E.; Mallin, K.; Loomis, A.; Gay, G.; Palis, B.; Thoburn, K.; Gress, D.; McKellar, D.P.; Shulman, L.N.; et al. Using the National Cancer Database for Outcomes Research: A Review. JAMA Oncol. 2017, 3, 1722-1728. [CrossRef]

18. National Cancer Data Base Participant User File (PUF) Data Dictionary. Available online: https://www.facs.org/- / media / files / quality-programs / cancer/ncdb/puf_data_dictionary.ashx (accessed on 1 February 2020).

19. Heinze, G.; Wallisch, C.; Dunkler, D. Variable selection-a review and recommendations for the practicing statistician. Biom. J. 2018, 60, 431-449. [CrossRef]

20. Pachera, S.; Nishio, H.; Takahashi, Y.; Yokoyama, Y.; Oda, K.; Ebata, T.; Igami, T.; Nagino, M. Undifferentiated embryonal sarcoma of the liver: Case report and literature survey. J. Hepatobiliary Pancreat. Surg. 2008, 15, 536-544. [CrossRef]

21. Webber, E.M.; Morrison, K.B.; Pritchard, S.L.; Sorensen, P.H.B. Undifferentiated embryonal sarcoma of the liver: Results of clinical management in one center. J. Pediatr. Surg. 1999, 34, 1641-1644. [CrossRef]

22. Lack, E.E.; Schloo, B.L.; Azumi, N.; Travis, W.D.; Grier, H.E.; Kozakewich, H.P. Undifferentiated (embryonal) sarcoma of the liver. Clinical and pathologic study of 16 cases with emphasis on immunohistochemical features. Am. J. Surg. Pathol. 1991, 15, 1-16. [CrossRef]

23. Walker, N.I.; Horn, M.J.; Strong, R.W.; Lynch, S.V.; Cohen, J.; Ong, T.H.; Harris, O.D. Undifferentiated (embryonal) sarcoma of the liver: Pathologic findings and long-term survival after complete surgical resection. Cancer 1992, 69, 52-59. [CrossRef]

24. Chen, L.E.; Shepherd, R.W.; Nadler, M.L.; Chapman, W.C.; Kotru, A.; Lowell, J.A. Liver transplantation and chemotherapy in children with unresectable primary hepatic malignancies: Development of a management algorithm. J. Pediatr. Gastroenterol. Nutr. 2006, 43, 487-493. [CrossRef]

25. Upadhyaya, M.; McKiernan, P.; Hobin, D.; Kelly, D.A.; Brown, R.; Lloyd, C.; Buckels, J.; Millar, A.J.W.; Degoyet, J.D.; Mirza, D.F. Primary hepatic sarcomas in children-a single-center experience over 19 years. J. Pediatr. Surg. 2010, 45, 2124-2128. [CrossRef] [PubMed]

26. Walther, A.; Geller, J.; Coots, A.; Towbin, A.; Nathan, J.; Alonso, M.; Sheridan, R.; Tiao, G. Multimodal therapy including liver transplantation for hepatic undifferentiated embryonal sarcoma. Liver Transpl. 2014, 20, 191-199. [CrossRef] [PubMed]

27. Techavichit, P.; Masand, P.M.; Himes, R.W.; Abbas, R.; Goss, J.A.; Vasudevan, S.A.; Finegold, M.J.; Heczey, A. Undifferentiated embryonal sarcoma of the liver (UESL): A single-center experience and review of the literature. J. Pediatr. Hematol. Oncol. 2016, 38, 261-268. [CrossRef]

28. Murawski, M.; Scheer, M.; Leuschner, I.; Stefanowicz, J.; Bonar, J.; Dembowska-Bagińska, B.; Kaliciński, P.; Koscielniak, E.; Czauderna, P.; Fuchs, J. Undifferentiated sarcoma of the liver: Multicenter international experience of the Cooperative Soft-Tissue Sarcoma Group and Polish Paediatric Solid Tumor Group. Pediatr. Blood Cancer 2020, 67, e28598. [CrossRef] [PubMed] 
29. Yu, X.-H.; Huang, J.; Ge, N.-J.; Yang, Y.-F.; Zhao, J.-Y. Recurrent undifferentiated embryonal sarcoma of the liver in adult patient treated by pembrolizumab: A case report. World J. Clin. Cases 2021, 9, 2281-2288. [CrossRef] [PubMed]

30. Sánchez-Morales, E.G.; Clemente-Gutiérrez, E.U.; Alvarez-Bautista, E.F.; Santes-Jasso, O.; Carpinteyro-Espin, P.; Mercado Miguel, A. Undifferentiated embryonal sarcoma of the liver in adult patient: A report of two cases. Ann. Hepatobiliary Pancreat. Surg. 2018, 22, 269-273. [CrossRef]

31. Almogy, G.; Lieberman, S.; Gips, M.; Pappo, O.; Edden, Y.; Jurim, O.; Simon Slasky, B.; Uzieli, B.; Eid, A. Clinical outcomes of surgical resections for primary liver sarcoma in adults: Results from a single centre. Eur. J. Surg. Oncol. 2004, 30, 421-427. [CrossRef]

32. Dhanasekaran, R.; Hemming, A.; Salazar, E.; Cabrera, R. Rare case of adult undifferentiated (embryonal) sarcoma of the liver treated with liver transplantation: Excellent long-term survival. Case Rep. Hepatol. 2012, 2012, 519741. [CrossRef]

33. Leuschner, I.; Schmidt, D.; Harms, D. Undifferentiated sarcoma of the liver in childhood: Morphology, flow cytometry, and literature review. Hum. Pathol. 1990, 21, 68-76. [CrossRef]

34. Kiani, B.; Ferrell, L.D.; Qualman, S.; Frankel, W.L. Immunohistochemical analysis of embryonal sarcoma of the liver. Appl Immunohistochem. Mol. Morphol. 2006, 14, 193-197. [CrossRef]

35. Lee, K.H.; Maratovich, M.N.; Lee, K.-B. Undifferentiated embryonal sarcoma of the liver in an adult patient. Clin. Mol. Hepatol. 2016, 22, 292-295. [CrossRef] [PubMed]

36. Li, X.-W.; Gong, S.-J.; Song, W.-H.; Zhu, J.-J.; Pan, C.-H.; Wu, M.-C.; Xu, A.-M. Undifferentiated liver embryonal sarcoma in adults: A report of four cases and literature review. World J. Gastroenterol. 2010, 16, 4725-4732. [CrossRef] [PubMed]

37. Kelly, M.J.; Martin, L.; Alonso, M.; Altura, R.A. Liver transplant for relapsed undifferentiated embryonal sarcoma in a young child. J. Pediatr. Surg. 2009, 44, e1-e3. [CrossRef] [PubMed]

38. Babu, B.I.; Bigam, D.L.; Gilmour, S.M.; Dajani, K.Z.; Shapiro, A.M.J.; Kneteman, N.M. Liver Transplantation in Locally Unresectable, Undifferentiated Embryonal Cell Sarcoma. Transpl. Direct 2021, 7, e654. [CrossRef] 